\title{
A Methodology for Assessing the Quality of Working Environment: Example of Research Proposal
}

\author{
Miriama Piňosová ${ }^{1, *}$, Miriam Andrejiová ${ }^{2}$ \\ ${ }^{1}$ Technical University of Košice, Faculty of Mechanical Engineering, Department of Process and Environmental Engineering, Park Komenského 5, \\ Košice, Slovakia \\ ${ }^{2}$ Technical University of Košice, Faculty of Mechanical Engineering, Department of Applied Mathematics and Informatics, Letná 9, Košice, Slovakia
}

\begin{abstract}
Objectives: This contribution is devoted to the experimental proposal of the methodology for a comprehensive assessment of the working environment quality. Methods: The evaluation was based on a basic assumption that the human organism during its work on different jobs affects various risk factors. We assume an ideal working environment with optimal or "zero" values of operating factors. Before determining the appropriate method of evaluation is appropriate to combine qualitative and quantitative assessment, creating a system for evaluating the parameters of the working environment that reflects: the nature of the impact parameters of the working environment, duration of effect, simultaneously operating range of risk factors and magnitude of the impact of individual parameters of the working environment. Results: The evaluation process in this case, enters workplace factors: noise, vibration, lighting, dust, electromagnetic fields, radiant heat and ergonomics, stress and safety factors. The most important step is the selection and evaluation that will be based on an evaluation of information and also interviewed people from expert's evaluation. The experiment was focused on four basic physical factors (noise, vibration, dust and lighting) working environment, which are among the most risky in terms of assessing the health of employees and duration of exposure in the workplace during their work shift. Conclusions: Computation of the final evaluation factor level work environment in workplace is real work load value equal to $\vartheta=0.5027$. In the final step of the proposed methodology based on point spread, we concluded that the risk is insignificant, the system is safe. The methodology presented in this paper describes the authors' idea about how to resolve this issue. The presented results are based on past experience in the field of measurement and evaluation of environmental factors, the authors actually perform.
\end{abstract}

Keywords: Saaty methods, risk assessment, comprehensive assessment, experimental proposal

\section{Introduction}

Risk assessment is the process of qualitative and quantitative risk assessment for occupational health and safety of workers. The more negative factors applied to the working environment, the greater the negative effects on the human organism. In assessing the working environment are used various methods and procedures designed to assess the possibility of harm. Therefore it is necessary to choose a suitable complex multi-criteria method, which, according to obtained information could determine the size of load of a man within the working environment. Selection criteria for assessment are not simple, because there are many indicators that characterize the working environment load. Before the assessment method is determined, it is appropriate to combine qualitative and quantitative assessment, 
thereby establishing a system for measurement of working environment, taking into account: the nature of the impacts of the working environment parameters, duration of the impact, the range of risk factors operating simultaneously, and the magnitude of the impact of individual parameters of the working environment.

With the mathematical formulation can be reached the target state, which is the idea of a display of the objective complete working environment quality in the spatial coordinates that define the different views, approaches and needs of the specification of the working environment parameters. In the designing of an experimental methodology of a comprehensive assessment of the quality of working environment we will build on the condition that the worker is affected during his work at different job positions by various risk factors. These factors vary by their intensity and duration on which depends their influence on human organism. To quantify these effects is difficult because:

- Each parameter in the working environment requires a different approach in analysing its effect on humans,

- Each parameter has a wide range of effects,

- The impact of individual risk factors varies with time and change of working activity,

The perception of the effects of the working environment is significantly an individual matter.

\section{Experimental Section}

It is important to determine also whether the environment will be evaluated by one criterion or we have more criteria available. In our case we propose to deal with the evaluation of multiple criteria simultaneously. We propose the following evaluation procedure:

- Selection of the methods of the working environment quality assessment,

- Selection and measurement of the risk factors,

- Determining the weights of the risk factors,

- Normalisation of the measured values,

- Calculation of the total load,

- Risk assessment (determination of the risk acceptability).

2.1 Selection of the Methods of the Working Environment Quality Assessment

Methods of decision making in general, present the summary of rules and procedures, using which we can come to choosing the best solution. The current situation offers us a wide range of methods of decision making. If we use a distribution based on mutual relation of empiricism and theory contained in the individual methods, it is possible to divide them into three groups of empirical, heuristic and exact methods.

In solving practical problems such as the comprehensive assessment of the working environment quality is appropriate to use one of the following methods of multi-criteria decision making. Specific methods, which can be used by a comprehensive assessment, can be as follows: point method of assessment, proportion index method, Decision Matrix Method (DMM), Forced Decision Matrix Method (FDMM), Analytic Hierarchy Process (AHP), method of quantitative comparison (Fuller method, ranking method, etc.).

The specified methods of multi-criteria decision making vary mainly according to how they determine so called weight of individual criterion. The comprehensive assessment of working environment quality to determine the weights of the criteria we use one of the exact methods and the analytical multilevel evaluation method AHP, which provides a framework for effective decisions in complex decision making situations, it helps simplify and accelerate the natural process of decision making process.

\subsection{Selection and measurement of the risk factors}

By the comprehensive assessment of the working environment is evaluated the interaction of all risk factors. In this case enter the process the workplace factors: noise, vibration, lighting, air purity, or dust, electromagnetic fields, ergonomics, radiant heat, physical stress, hygienic factors and safety factors. The most important step is the selection and evaluation will be based on an evaluation of information of interviewed people and also from expert opinions. The next step of a comprehensive evaluation is the measurement of risk factors. The results should then be processed to evaluate and draw conclusions from them.

\subsection{Determining the weights of the risk factors}

The Analytic Hierarchy Process (AHP), introduced by Thomas Saaty (1980), method provides a comprehensive and coherent approach to structuring the problem to quantify the elements that relate to the overall objectives and for evaluating the alternative solutions. Before the application of the method, the valuation entity must define any criteria on the basis of which the evaluation will be conducted.

This method is based on pairwise comparisons of 
the degree of significance of individual criteria. The evaluation is based on so called expert estimation, by which the experts in the field can compare the mutual effect of two factors. These evaluate on the basis of the scale [equal-weak-moderate-strong-verystrong], and to this wording evaluation correspondents following values [1-3-5-7-9]. Saaty's point rating scale is in the Table 1.

Tab. 1: Saaty's point rating scale.

\begin{tabular}{|l|l|}
\hline Number of points & Explanation \\
\hline 1 & Criteria are equally important. \\
\hline 5 & $\begin{array}{l}\text { The first criterion is slightly more } \\
\text { important than the second one. }\end{array}$ \\
\hline 7 & $\begin{array}{l}\text { The first criterion is strongly more } \\
\text { important than the second one. }\end{array}$ \\
\hline 9 & $\begin{array}{l}\text { The first criterion is demonstrably } \\
\text { (very strongly) more important } \\
\text { than the second one. }\end{array}$ \\
\hline & $\begin{array}{l}\text { The first criterion je absolutely } \\
\text { (extremely) more important than } \\
\text { the second one. }\end{array}$ \\
\hline
\end{tabular}

Values 2, 4, 6, and 8 may be used for a more detailed differentiation of sizes of criterion pair preferences.

The application of the Saaty's method is based on the creation of the Saaty's matrix $\mathbf{S}$. The matrix elements $s_{i j}(i, j=1,2, \ldots, n)$ represent the estimated percentages of weights of $n$ criteria (how many times one criterion is more important than the other one). For the $\mathbf{S}$ matrix elements it applies that

$s_{i j}>0, s_{i i}=1, s_{i j}=\frac{1}{s_{j i}}, \quad$ for $\quad i, j=1,2, \ldots, n$

consequently

$\mathbf{S}=\left(\begin{array}{cccc}1 & s_{12} & \cdots & s_{1 n} \\ s_{21} & 1 & \cdots & s_{2 n} \\ \vdots & \vdots & \cdots & \vdots \\ s_{n 1} & s_{n 2} & \cdots & 1\end{array}\right)$

Criterion weights may be identified, for example, by an exact approach based on the calculation of eigenvalues and eigenvectors of the Saaty's matrix or by normalised geometric means of lines in the Saaty's matrix.

In the case of the exact approach, criterion weights are identified using the $\mathbf{w}$ eigenvector, corresponding to the maximum eigenvalue $\lambda_{\max }$ of the Saaty's matrix $\mathbf{S}$ which can be calculated using the equation

$$
\left(\mathrm{S}-\lambda_{\max } \mathrm{I}\right) \mathbf{w}=\mathbf{0}
$$

where $\mathbf{I}$ is the unit matrix of the $n$-th order and $\mathbf{0}$ is the zero matrix.

The normalised weight of the $i$-th criterion $v_{\mathrm{i}}$ is calculated using the formula

$v_{i}=\frac{w_{i}}{\|\mathbf{w}\|}, i=1,2, \ldots, n \quad$ where $\quad\|\mathbf{w}\|=\sum_{i=1}^{n} w_{i}$

Another simple way to determine the weighting of the criteria from Saaty's matrix $\mathbf{S}$ is to calculate the geometric mean $b$ i of the $i$-th row of Saaty's matrix $\mathbf{S}$. The geometric mean $b_{\text {i }}$ is calculated using the formula

$b_{i}=\sqrt[n]{\prod_{i=1}^{n} s_{i j}}, i=1,2, \ldots, n$

The normalised weight of the $i$-th criterion $v_{\text {i }}$ can be calculated using the following formula:

$v_{i}=\frac{b_{i}}{\sum_{i=1}^{n} b_{i}}, i=1,2, \ldots, n \quad$ where $\quad \sum_{i=1}^{n} v_{i}=1, v_{i} \geq 0$

Calculation of the vector of weights from the paired comparison matrix is usually part of the special programs implemented by AHP method. The calculation is also possible to realise in Excel with the utilisation of so called Wielandt theorem. Such mathematical calculation is used also by the software SANNA - System for Analysis of Alternatives. It is freeware that enables to solve multicriteria decision problems by several methods. The application utilises five methods of assessment (TOPSIS, WSA, ELECTRE I, PROMETHEE II and MAPPAC) and enables to determine the weights by three methods (Point method, Fuller's method and Saaty's procedure) and to solve multi-criteria problems by seven methods (TOPSIS, WSA, ELECTRE I, ELECTRE III, PROMETHEE II, ORESTE and MAPPAC). With SANNA it is possible to solve up to 100 variations and 50 criteria. 


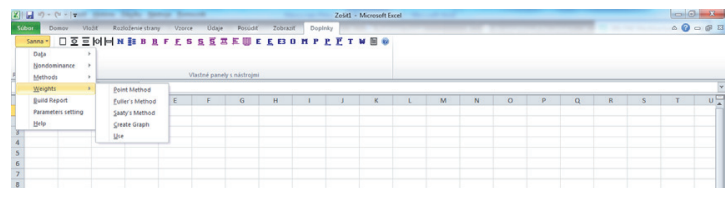

Fig. 1: Sanna-basic menu entry Weights.

The resulting Saaty's matrix $\mathbf{S}$ is

$\mathrm{S}=\left(\begin{array}{cccc}1 & 3 & 4 & 5 \\ 1 / 3 & 1 & 2 & 3 \\ 1 / 4 & 1 / 2 & 1 & 2 \\ 1 / 5 & 1 / 3 & 1 / 2 & 1\end{array}\right)$

The normalised weights of the risk factors are in the Table 2. The evaluation results indicate that factor F1 (Noise) has the highest weight $\left(v_{1}=0.5462\right)$. The order of importance of the risk factors is as follows: $F 1>F 2>F 3>F 4$.

Tab. 2: Resulting normalised weights of factors.

\begin{tabular}{|l|l|l|}
\hline Factor & Weight & Weight (\%) \\
\hline F1 (Noise) & $\mathbf{0 . 5 4 6 2}$ & 54.62 \\
\hline F2 (Dust) & $\mathbf{0 . 2 3 2 3}$ & 23.23 \\
\hline F3 (Lighting) & $\mathbf{0 . 1 3 7 7}$ & 13.77 \\
\hline F4 (Vibration) & $\mathbf{0 . 0 8 3 7}$ & 8.37 \\
\hline
\end{tabular}

\subsection{Normalisation of the measured values}

The calculation of the measured values for indicators in the interval $<0,1>$ can be performed on the relation:

$$
F_{i j}=1-\frac{L_{U}-L_{A}}{L_{U}-L_{L}}
$$

where $F_{i j}$ standardized value of the basic indicator $j$ from the class of the factor $i, L_{U}$ upper limit value of the factor, $L_{L}$ lower limit value of the factor and $L_{A}$ actual (measured) value of the factor.

Calculation procedure: we will assume the case of the ideal work environment with optimal or "zero" values of randomly selected factors of the working environment. These factors include noise, air purity, light intensity, and safety factors.

Noise (F1): according to the Regulation of the Government of the Slovak Republic 115/2006 The Collection of Laws on Minimum Health and Safety Requirements for the Protection of Workers from the Risks Related to Exposure to Noise is the permissible value of the noise exposure level for the IV group.
"Activity in which noisy machines and tools are used or which is carried out in a noisy environment and which does not meet the conditions for inclusion in groups I, II and III" according to the Decree of the Ministry of Health of the Slovak Republic 448/2007 Collection of laws on the details of labor factors and the working environment in relation to the categorization of work from the point of view of health risks and on the design requirements for classifying works. In the case of noise, we determine quantities for Eq. (8) as follows:

$L_{U}$ - upper limit value of the noise exposure level; $L_{\mathrm{AEX}, 8 \mathrm{~h}}=80 \mathrm{~dB}$ for work group IV.,

$L_{L}$ - lower limit value of the noise exposure level; $L_{\mathrm{AEX}, 8 \mathrm{~h}}=40 \mathrm{~dB}$ for work group I.,

$L_{A}$ - actual (measured) value of the noise exposure level; LAEX,8h $=60 \mathrm{~dB}$.,

$F_{i j}$ - standardized value of the noise exposure level;

Noise (F1) $\quad F_{i j}=1-\frac{80-60}{80-40}=\mathbf{0 . 5}$.

Dust (F2): We evaluate air cleanness by the questionnaire method. For each positive answer (yes) we assign 10 points and for each negative (no) 0 points. After the evaluation, we perform the normalization according to Eq. (8).

Tab. 3: Questionnaire.

\begin{tabular}{|c|c|c|}
\hline & \multirow{3}{*}{$\frac{\text { points }}{2}$} \\
\hline & & \\
\hline 1. & Are there aerosol sources at the workplace? & \\
\hline 2. & Are the sources of secondary dust in the workplace? & 0 \\
\hline 3. & $\begin{array}{l}\text { Are Workplace arrangements being made to reduce or reduce } \\
\text { removal? }\end{array}$ & 8 \\
\hline 4. & $\begin{array}{l}\text { Was the measurement of air dust concentration measured at } \\
\text { the workplace? }\end{array}$ & 10 \\
\hline 5. & $\begin{array}{l}\text { Did the values exceeding the maximum concentration values in } \\
\text { the air have been detected? }\end{array}$ & 4 \\
\hline 6. & Are there technical and organizational measures? & 7 \\
\hline 7. & Are employees of an effective PPE? & 8 \\
\hline 8. & Do workers have any work-related health problems? & 2 \\
\hline 9. & $\begin{array}{l}\text { Are workers satisfied with the cleanness of the working } \\
\text { atmosphere? }\end{array}$ & 3 \\
\hline 10. & Do preventive medical check-ups take place? & 10 \\
\hline & Total & 54 \\
\hline
\end{tabular}

In some cases, however, it is not possible to make a clear decision in this case, we use a scale 
of $0 \div 10$ and, according to the detected state at the workplace, we choose the value that most closely reflects the state of the given factor in the valued working environment. In other possible questionnaires, we do the same.

$L_{U}-$ maximum number of points obtained 100,

$L_{L}-$ minimum number of points obtained 0 ,

$L_{A}-$ actual number of points obtained 54 ,

$F_{i j}$ - standardized value of the air quality level;

Dust (F2) $\quad F_{i j}=1-\frac{100-46}{100-0}=\mathbf{0 . 4 6}$.

Similarly, normalized values for light intensity and safety factors were calculated.

Lighting (F3) $\quad F_{i j}=1-\frac{700-620}{700-500}=\mathbf{0 . 6 0}$.

Vibration (F4) $\quad F_{i j}=1-\frac{5-1.3}{5-2.5}=\mathbf{0 . 4 8}$.
The measured normalised values of the risk factor are in the Table 4.

Tab. 4: Measured normalised values of the risk factors.

\begin{tabular}{|l|l|l|l|l|}
\hline Factor & \multicolumn{1}{l|}{$L_{U}$} & \multicolumn{1}{l|}{$L_{A}$} & \multicolumn{1}{l|}{$L_{L}$} & \multicolumn{1}{l|}{$F_{i j}$} \\
\hline F1 (Noise) & 80 & 60 & 40 & 0.50 \\
\hline F2 (Dust) & 100 & 46 & 0 & 0.46 \\
\hline F3 (Lighting) & 700 & 620 & 500 & 0.60 \\
\hline F4 (Vibration) & 5.0 & 1.3 & 2.5 & 0.48 \\
\hline
\end{tabular}

2.5 Calculation of the total load

Interpretation of the final coefficient calculation evaluating the level of the working environment at a workplace or in a group of workplaces is based on Table 5 and Figure 2.

Manual calculation is appropriate to process according to the procedure set in Table 5 .

Tab. 5: Procedure of calculation of the factor values of the working environment at n-workplace or valid for n-worker.

\begin{tabular}{|c|c|c|c|c|c|c|c|c|c|c|c|}
\hline \multirow{3}{*}{$\begin{array}{l}\text { Factors of the working } \\
\text { environment } \\
\text { Factor } 1\end{array}$} & \multirow{3}{*}{$\begin{array}{l}\text { Normalised weight of a } \\
\text { vector } \\
v_{1}\end{array}$} & \multicolumn{9}{|c|}{ Workplaces } & \multirow{8}{*}{$\begin{array}{l}\text { Evaluation of } \\
\text { each factor at all } \\
\text { workplaces }\end{array}$} \\
\hline & & \multicolumn{2}{|c|}{1} & \multicolumn{2}{|c|}{2} & \multicolumn{2}{|c|}{$j$} & $\ldots$ & \multicolumn{2}{|c|}{$n$} & \\
\hline & & $\mathrm{F}_{11}$ & $\vartheta_{11}$ & $\mathrm{~F}_{12}$ & $\vartheta_{12}$ & $\mathrm{~F}_{1 \mathrm{j}}$ & $\vartheta_{1 j}$ & & $\mathrm{~F}_{1 \mathrm{n}}$ & $\vartheta_{1 \mathrm{n}}$ & \\
\hline Factor 2 & $v_{2}$ & $\mathrm{~F}_{21}$ & $\vartheta_{21}$ & $\mathrm{~F}_{22}$ & $\vartheta_{22}$ & $\mathrm{~F}_{2 \mathrm{j}}$ & $\vartheta_{2 \mathrm{j}}$ & & $\mathrm{F}_{2 \mathrm{n}}$ & $\vartheta_{2 \mathrm{n}}$ & \\
\hline \multicolumn{11}{|l|}{$\ldots \ldots$} & \\
\hline Factor i & $v_{\mathrm{i}}$ & $\mathrm{F}_{\mathrm{i} 1}$ & $\vartheta_{\mathrm{i} 1}$ & $\mathrm{~F}_{\mathrm{i} 2}$ & $\vartheta_{\mathrm{i} 2}$ & $F_{i j}$ & $\vartheta_{\mathrm{ij}}$ & & $F_{\text {in }}$ & $\vartheta_{\text {in }}$ & \\
\hline \multicolumn{11}{|l|}{$\ldots .}$. & \\
\hline Factor m & $v_{\mathrm{m}}$ & $\mathrm{F}_{\mathrm{m} 1}$ & $\vartheta_{\mathrm{m} 1}$ & $\mathrm{~F}_{\mathrm{m} 2}$ & $\vartheta_{\mathrm{m} 2}$ & $\mathrm{~F}_{\mathrm{mj}}$ & $\vartheta_{\mathrm{mj}}$ & & $\mathrm{F}_{\mathrm{mn}}$ & $\vartheta_{\mathrm{mn}}$ & \\
\hline \multicolumn{2}{|c|}{ Evaluation of all parameters according to workplaces } & & $\vartheta_{1}$ & & $\vartheta_{2}$ & & $\vartheta_{\mathrm{j}}$ & $\ldots$ & & $\vartheta_{\mathrm{n}}$ & $\vartheta_{p}=\frac{\sum_{j=1} \vartheta_{j}}{n}$ \\
\hline
\end{tabular}

The indicators listed in Table 5 are influenced by the standardized weight vectors in the process of evaluating a particular work environment, which is quantified by the general considerations of the load on the work environment by the set factors.

In our case, in the case of a complex assessment of the working environment, we assessed four risk factors of the working environment $(m=4)$ in one workplace $(n=1)$, respectively for one employee.

The actual workload values are shown in table 6.

The overall workload is $\vartheta=0.5027$, which can be considered a normal (optimal) state.
Tab. 6: Actual loading of the working environment (1 workstation or 1 worker).

\begin{tabular}{|l|l|l|l|}
\hline Factor & \multicolumn{1}{l}{$\begin{array}{l}\text { Normalised } \\
\text { value }\end{array}$} & \multicolumn{1}{l|}{$\begin{array}{l}\text { Normalised value of } \\
\text { the factors weight }\end{array}$} & Actual load \\
\hline F1 (noise) & 0.50 & 0.5462 & 0.2731 \\
\hline F2 (dust) & 0.46 & 0.2323 & 0.1068 \\
\hline F3 (lighting) & 0.60 & 0.1377 & 0.0826 \\
\hline F4 (vibration) & 0.48 & 0.0837 & 0.0402 \\
\hline Overall load $\vartheta$ & & 0.5027 \\
\hline
\end{tabular}




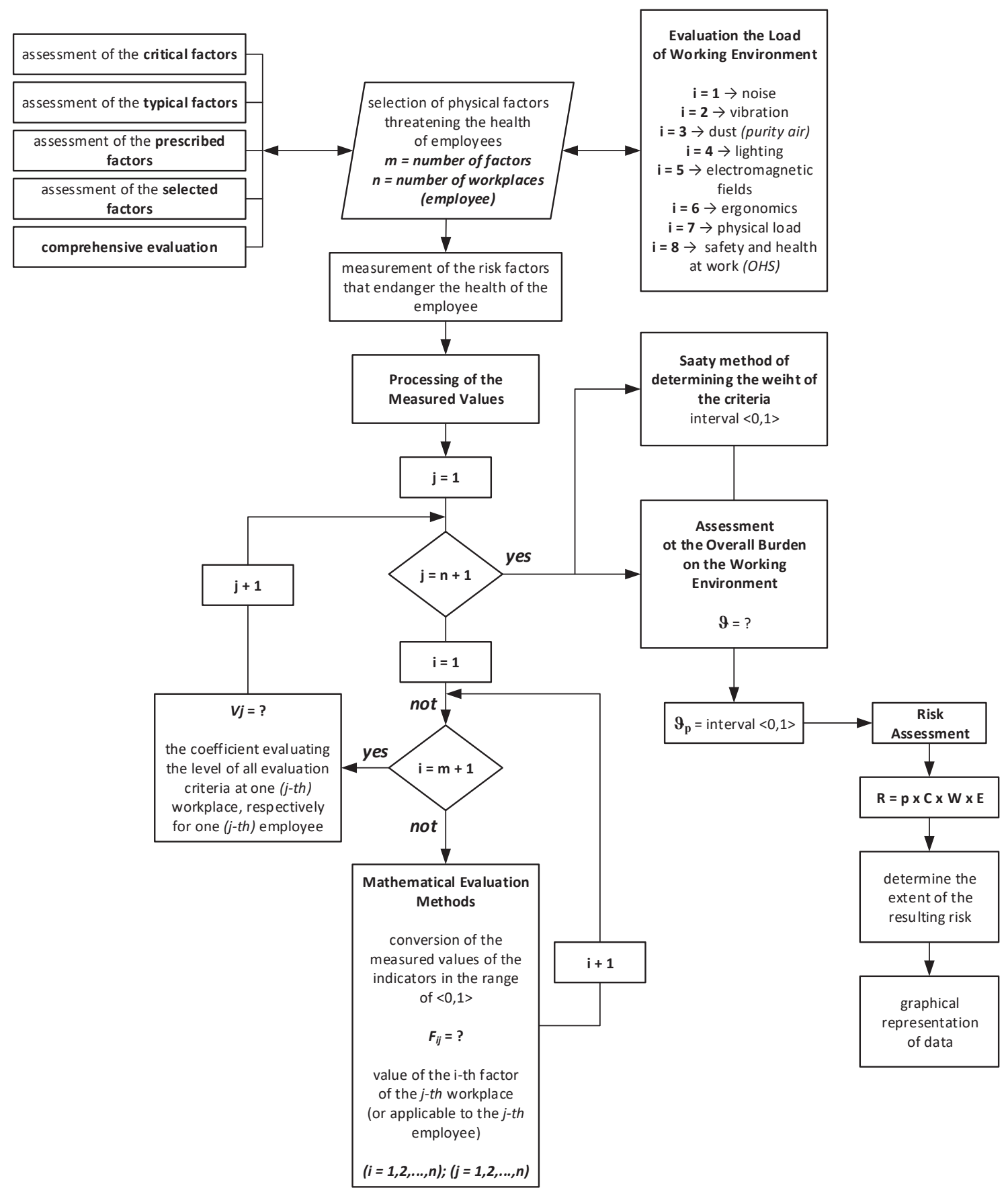

Fig. 2: Procedure of the calculation of the working environment factor values at the n-workplace.

2.6 Risk assessment (determination of the risk acceptability) If the risk (R) is the probability of formation and at the same time the severity of consequences or adverse event, we state that the risk is the function of two basic parameters: probability (p) and consequence (C).
Mathematically expressed: $\mathbf{R}=\mathbf{p} \mathbf{x} \mathbf{C}$. And the symbol $x$ expresses the type of function according to the type of evaluation (it can be a matrix or conjunction). In our opinion, a straightforward risk assessment process in five steps is suitable: Step 1: Identifying hazards 
and persons at risk, Step 2: Risk assessment and prioritizing, Step 3: Deciding on preventive measurements, Step 4: Taking action, Step 5: Monitoring and control.

Choice of approach to the assessment will depend on the nature of the workplace (e.g. stable or temporary operation), the type of process (e.g. repetitive activities, developing/changing processes, work on the contract), the task being performed (e.g. repetitive, occasional or high risk) and technical complexity.

Criteria of system safety evaluation and risk assessment are not firm. As accepted risk is considered the risk which the persons in concern taking into account all operational and human conditions will be willing to bear. In our case, the risk assessment method was selected the point method. Compared to the classical definition of risk is by the assessment of the risk level utilized the expanded definition of the risk in the following form:
$\mathbf{R}($ risk $)=\mathbf{p}($ probability $) \times \mathbf{C}($ consequence $) \times$ OHS $($ ef the safety and health at work) $\times \mathbf{E}($ period of exposi 1 where $\mathbf{p}$ - probability we determine on the basis of the Gauss function of the density of the probability normal distribution and overall load of the working environment adapted for our case study.

and: $\quad \mathrm{p}=5-\frac{1}{0,1 \sqrt{2 \pi}} \mathrm{e}^{-\frac{(\vartheta-0,5)^{2}}{2 \cdot 0,1^{2}}}$

then: $\quad \mathrm{R}=\left(5-\frac{1}{0,1 \sqrt{2 \pi}} \mathrm{e}^{-\frac{(9-0,5)^{2}}{2.0,1^{2}}}\right) \cdot \mathrm{C} \cdot \mathrm{OHS} \cdot \mathrm{E}$

Risk - final indicator, which is the product of the four values of risk parameters. The lowest value can be 1 and the highest 625 (Table 7). The score range is classified into five risk categories according to the points: Insignificant, Negligible risk; acceptable, Less significant risk; Adverse risk; Significant risk and Unacceptable risk.

$$
\mathrm{R}=\left(5-\frac{1}{0,1 \sqrt{2 \pi}} \mathrm{e}^{-\frac{(\vartheta-0,5)^{2}}{2.0,1^{2}}}\right) \cdot \mathrm{C} \cdot \mathrm{OHS} \cdot \mathrm{E}=\left(5-\frac{1}{0,1 \sqrt{2 \pi}} \mathrm{e}^{-\frac{(0,5027-0,5)^{2}}{2.0,1^{2}}}\right) \cdot 1 \cdot 3 \cdot 4=12,14
$$

Tab. 7: Determination of the resulting risk.

\begin{tabular}{l|l|l|l|l|l|}
\multicolumn{2}{l}{ Risk } & Risk category & Point spread & Safety assessment & \multicolumn{1}{l|}{$\begin{array}{l}\text { Measures } \\
\text { description }\end{array}$} \\
\hline $\begin{array}{l}\text { Irrelevant, } \\
\text { insignificant risk }\end{array}$ & I. & $1-20$ & system is safe & $\begin{array}{l}\text { it is not necessary to take } \\
\text { measures }\end{array}$ & $\begin{array}{l}\text { no injury, minor financial } \\
\text { loss }\end{array}$ \\
\hline Acceptable risk & II. & $21-50$ & $\begin{array}{l}\text { system is provided with } \\
\text { safe service training }\end{array}$ & $\begin{array}{l}\text { possibility for improve- } \\
\text { ment, corrective plan }\end{array}$ & $\begin{array}{l}\text { first aid, medium } \\
\text { financial loss }\end{array}$ \\
\hline Adverse risk & III. & $51-250$ & $\begin{array}{l}\text { risk cannot be accepted } \\
\text { without safeguards }\end{array}$ & $\begin{array}{l}\text { safety measures is } \\
\text { needed }\end{array}$ & $\begin{array}{l}\text { necessary medical } \\
\text { treatment, high } \\
\text { financial loss }\end{array}$ \\
\hline Significant risk & IV. & $251-500$ & $\begin{array}{l}\text { system is unsafe, the } \\
\text { possibility of injury }\end{array}$ & $\begin{array}{l}\text { should take immediate } \\
\text { safety measures }\end{array}$ & $\begin{array}{l}\text { extensive injury, } \\
\text { large financial loss }\end{array}$ \\
\hline Unacceptable risk & V & $501-625$ & $\begin{array}{l}\text { system is unacceptable, } \\
\text { the threat of permanent } \\
\text { injury }\end{array}$ & system shutdown & $\begin{array}{l}\text { death, huge financial } \\
\text { loss }\end{array}$ \\
\hline
\end{tabular}

Considering the subjective evaluation and selection of point values in the evaluation of risk parameters is not so important endpoints risk value for individual hazards, such as identification of specific hazards, threats to the professional as a threat to a lower point value of risk may cause injury more often than the risk of higher value.

\section{Results and Discussion}

An analysis of the current state of assessment of the working environment points out that in practice there is a way of partially assessing the workload. This means that the effect of each factor acting on the organization of the employee during his / her work is evaluated separately, independently of the other environmental factors present. For this reason, it is essential to address the issues of cumulative and synergistic effects when dealing with a comprehensive assessment of the quality of the working environment, particularly because this serious problem is not yet legislatively addressed. At present, however, there is not enough practical 
experience in Slovakia for their qualified assessment as well as the interpretation of their results, there is no directive or other implementing regulation laying down a procedure for assessing the cumulative and synergic effects.

Issuing legislation to assess the possibility of generating cumulative and synergistic effects is not defined in the law, but issuing such a standard is necessary. Nevertheless, it should be stressed that each individual case is completely individual and needs to be thoroughly studied and subsequently evaluated. The synergistic effect is therefore to multiply or combine many or long-acting stimuli until they produce an effect. Thus, many harmful impacts may appear to be time-consuming or to a lesser extent innocuous or, on the contrary, positive, ineffective or unnecessary.

In spite of all this, we have attempted to process a case study based on the condition of the synergistic effect of environmental factors on the health status of employees in this work with available statistical mathematical methods.

Comprehensive evaluation of the environmental quality is a new innovative approach for assessing the effects on humans. It should be noted that this issue is complicated and therefore there are many approaches to its solution. The methodology presented in this paper describes the authors' idea about how to resolve this issue. The presented results are based on past experience in the field of measurement and evaluation of environmental factors, the authors actually perform.

\section{Acknowledgments}

This work was supported by the Slovak Research and Development Agency under the contract APVV-0432-12 (50\%) and APVV-15-0327 (50\%).

\section{References and Notes}

[1] Dado, M., Hudecová, D., Hnilica, R. (2012) Combined effects of lighting, noise and temperature on work performance. Acta Universitatis Matthiae Belii. Vol. 14, No. 1, p. 100-104.

[2] Drake, P.R. (1998) Using the Analytic Hierarchy Process in Engineering Education. Int. J. Engng. Ed. Vol. 14, No.3, p.191-196.

[3] Hnilica R. (2011) Development of framework for assessment of combined effects of risk factors. In: Acta Facultatis Technicae. XVI. 2011 (2): 31-37.

[4] Lumnitzer, E., Badida, M., Romanová, M. (2007) Hodnotenie kvality prostredia. p. 25-68.
[5] Lumnitzer, E., et al. (2013) Methodology of complex health risk assessment in industry 2. Publishers MUSKA sp. z o.o. Poland. p. 326

[6] Millet, I., Wedley, W.C. (2002) Modelling Risk and Uncertainty with the Analytic Hierarchy Process. Journal of Multi-Criteria Decision Analysis, 11: 97-107.

[7] Piňosová, M., Andrejiová, M., Lumnitzer, E. (2012) Analyzing clinical symptoms of the synergy of high exposure to noise and vibration on human health in productions. Pracovní lékařství. Vol. 64, No. 2-3. p. 103-111.

[8] Robson, M., Toscano, W. (2007) Risk Assessment for Environmental Health 1-611.

[9] Roháčová, I., Marková, Z. (2009) The Analysis of AHP method and its potential use in logistics. Acta Montanistica Slovaca. Ročník 14. (1) 103-112.

[10] Saaty, T. L. (2008) Decision making with the analytic hierarchy process. International Journal of Services Sciences, vol. 1, p. 83-98.

[11] Šubrt, T. et al. (2011) Economic and mathematical methods. Cenek, Plzeň.

[12] Vargas, L.G. (1990) An overview of the analytic hierarchy process and its applications. European Journal of Operational Research, 48: 2-8. 1990

[13] Zimmermann H.J. (2000) Multi-Criteria Decision Making Methods: A Comparative Study.

\section{Biographical notes}

Miriama Piňosová, Ing., PhD.: (1983) Student she graduated at the Technical University of Košice, Faculty of Mechanical Engineering, Department of Biomedical Engineering. Since the year 2007 she has been employed at the Department of Process and Environmental Engineering within the abovementioned Faculty; firstly as an internal PhD.-student and now she is an scientific researcher. Her professional orientation is focused on the methodology developed for evaluation of environmental factors with impact on human health.

Miriam Andrejiová, RNDr., PhD.: graduated in 1997 at Faculty of Science in Safarik University in Košice in field of mathematics and physics. She received PhD. in 2004 at Faculty of Science in Safarik University in Košice. Since 1998 she is working as assistant in the Department of Applied Mathematics and Informatics, Faculty of Mechanical Engineering, Technical University in Kosice. She is co-author of two monographs, some textbooks and many scientific and professional articles aimed at applying mathematical and statistical methods in practice. 